\title{
CLONING OF A GENE ENCODING PROTEIN BELONGING TO ABC TRANSPORTER INVOLVED IN BACTERIAL MAGNETIC PARTICLE SYNTHESIS IN MAGNETOSPIRILLUM MAGNETICUM AMB-1
}

\author{
ARIS TRI WAHYUDI \\ Department of Biology, Faculty of Mathematics and Natural Sciences, \\ Bogor Agricultural University, Bogor, Indonesia
}

\begin{abstract}
Magnetospirillum magneticum AMB-1 synthesizes intracellular magnetic particles, magnetite $\left(\mathrm{Fe}_{3} \mathrm{O}_{4}\right)$, enveloped by membrane called magnetosome under micro-aerobic conditions. Initial study of random transposon-based mutagenesis generated 62 nonmagnetic mutants of AMB-1 in a mini-Tn5 library. In order to identify a gene involved in bacterial magnetic particle (BMP) synthesis in the magnetic bacterium M. magneticum AMB-1, a nonmagnetic mutant from the library designated as NMA38-4, was analyzed. The amino acid sequence deduced from the gene directly interrupted by transposon, ORF4 (1482 bp), showed homology to ATP binding cassette $(\mathrm{ABC})$ transporter of Mesorhizobium loti with $62 \%$ identity and $74 \%$ similarity. It was strongly indicated by the occurrence of putative consensus sequence of ATP-binding motifs (ATPbinding protein). The ORF4 was subsequently cloned in pET-15b and the recombinant ORF4Histag fusion protein was heterologously expressed in Escherichia coli BL21 (DE3) pLysS. A $55 \mathrm{kDa}$ protein corresponding to the ORF4-Histag fusion protein was obtained after purification using $\mathrm{Ni}-\mathrm{NTA}$ column. This is the first report describing a gene cluster containing gene encoding protein belonging to $\mathrm{ABC}$ transporter organized in an operon which is involved in BMP synthesis.
\end{abstract}

Key words: Magnetospirillum magneticum AMB-1, Bacterial Magnetic Particle (BMP), ATP Binding Cassette $(\mathrm{ABC})$ Transporter, transposon mutagenesis.

\section{INTRODUCTION}

Magnetospirillum magneticum AMB-1 isolated from fresh water sediment (Matsunaga 1991) synthesizes bacterial magnetic particles (BMPs) of the iron mineral magnetite $\left(\mathrm{Fe}_{3} \mathrm{O}_{4}\right)$ enveloped by membrane called magnetosome, under microaerobic conditions. These intracellular single domain magnetic particles are aligned in chains with each individual crystal having a diameter of 50-100 $\mathrm{nm}$ enveloped by an organic membrane (Gorby et al. 1988; Matsunaga 1991). It is postulated that BMPs confer sensitivity of the bacterium to the earth's magnetic field lines for migration along oxygen and iron gradients. 
So far, only few magnetic bacterial strains can be cultivated under laboratory conditions in pure culture, these include M. magnetotacticum MS-1 (Blakemore et al. 1979) and M. magneticum AMB-1 (Matsunaga et al. 1991), and M. gryphiswaldense (Schleifer et al. 1991). These strains are usually used as model systems for the analysis of BMP synthesis. The capability of $M$. magneticum AMB-1 to grow on agar plate and liquid medium both under microaerobic and aerobic conditions (Matsunaga et al. 1992) makes the bacterium amenable for genetic manipulations to elucidate important metabolic mechanisms most especially for the complex process of BMP synthesis.

Since magnetic bacteria were first discovered (Blakemore 1975), only few genes were isolated namely recA (Berson et al. 1989), aroD (Berson et al. 1991), and mam22 (Okuda et al. 1996) from M. magneticum MS-1. In the previous studies, magA (Nakamura et al. 1995a) and mms16 (Okamura et al. 2001) genes were isolated from M. magneticum AMB-1. The magA gene functions for the iron transport across the BMP membrane. Mutation of this gene rendered the cells defective in iron uptake. The Mms 16 protein has a GTPAse activity for the invagination of the cytoplasmic membrane for the formation of the BMP membrane. Cells with inhibited GTPase activity showed that they produced disrupted BMPs.

Previously, a non-magnetic mutant of $M$. magneticum AMB-1, designated NMA38-4, was generated by mini-Tn5 transposon mutagenesis (Wahyudi et al. 2001). In the present study, we have identified a gene (ORF4) involved in BMP synthesis in $M$. magneticum AMB-1. This gene encoding protein which belongs to ABC transporter was cloned and heterologously expressed in E. coli as an ORF4-Histag fusion polypeptide. Mutation within this gene rendered $M$. magneticum AMB-1 was unable to synthesize BMPs. The aim of this study was to isolate and clone a gene (ORF4) from M. magneticum AMB-1 genome and express it in Escherichia coli BL21 (DE3) pLysS.

\section{MATERIALS AND METHODS}

\section{Bacterial Strains and Culture Conditions}

Escherichia coli DH5 $\alpha$ was routinely cultured in Luria broth (LB) (tryptone 5.0 $\mathrm{g} \mathrm{l}^{-1}, \mathrm{NaCl} 10 \mathrm{~g} \mathrm{l}^{-1}$, yeast extract $5.0 \mathrm{~g} \mathrm{l}^{-1}$ ) and E. coli BL21 (DE3) pLysS was cultured in LB supplemented with chloramphenicol $34 \mu \mathrm{g} \mathrm{ml} l^{-1}$ at $37^{\circ} \mathrm{C}$. Magnetospirillum magneticum AMB-1 (ATCC 700264) was cultured micro-aerobically in MSGM at $25^{\circ} \mathrm{C}$ (Blakemore et al. 1979). A nonmagnetic mutant, NMA38-4 (Wahyudi et al. 2001), was micro-aerobically cultured in MSGM supplemented with kanamycin (5 $\mu \mathrm{g} \mathrm{ml} \mathrm{m}^{-1}$.

\section{Observation of NMA38-4}

A nonmagnetic mutant, NMA38-4 cells (Wahyudi et al. 2001) was cultured until logarithmic phase and cells of this phase were observed under light microscopy (Olymphus BH2, Tokyo, Japan). Samarium-cobalt magnet was moved in different directions near the glass slide to determine the cells magnetic response. 
Bacterial magnetic particle synthesis in Magnetospirillum magneticum AMB-1 - Aris Tri Wahyudi.

\section{Isolation of Flanking DNA and Sequence Analysis}

Mutant DNA fragments flanking transposon in this work was isolated by inverse PCR after EcoRV digestion and circularization, using primers designed from the mini-Tn5Km1 sequence (Primer 1: 5'-GTA CCG AGC TCG AAT TC-3' and Primer 2: 5'-GAT CCT CTA GAG TCG AC-3'). The primers were directed outward from the transposon. A $1.3 \mathrm{~kb}$ inverse PCR product (Fig. 1) was purified from the gel by Gene Clean III Kit (Bio-101, Carlsbad, CA.) and sub-cloned in pCR2.1 (TA Cloning, Invitrogen, USA), designed pCR2.1-38.4. This recombinant plasmid was transformed into $E$. coli $\mathrm{DH} 5 \alpha$. The recombinant plasmid was subsequently isolated from E. coli by Qiaprep Miniprep (Qiagen, Gmbh, Germany) and used as a template for DNA sequencing. The DNA sequencing was performed using an automatic DNA sequencer ABI 377 (Perkin Elmer, USA). The DNA sequence was subsequently aligned against the complete genome sequence of $M$. magneticum AMB-1 (Matsunaga et al. 2005). A computer software package, LASERGENE (DNASTAR, Madison, WI) was used for DNA and protein sequence analysis. The sequence was further analyzed by performing homology searches using program of BLAST (Altchul et al. 1997) against the GenBank and EMBL DNA databases.

\section{Gene Cloning and Expression in Escherichia coli}

Based on the sequence of ORF4 (Fig. 1), two oligonucleotide primers (Primer P1: 5'-GGG GGA CAT ATG AGC GAC GTC GTC GAA-3' and Primer P2: 5'-GGG GGA TCC AAA TCA CGT GTC GTC CCC CCA-3') were designed (underlined nucleotides indicate $N d e \mathrm{I}$ and $B a m \mathrm{HI}$ sites, respectively). The recombinant plasmid pET15b-ORF4 was constructed by cloning of the PCR product amplified from ORF4 into the NdeI/BamHI site of expression vector pET15b (Novagen, USA). To amplify ORF4, a primer P1 with $N d e$ I site introduced at a start codon ATG, and primer P2 with the BamHI site introduced downstream of the stop codon (TGA) of the gene were used. The $50 \mu \mathrm{PCR}$ reaction mixture contained $100 \mathrm{ng} M$. magneticum AMB-1 genomic DNA, 2.5 U LA Taq (Takara, Tokyo, Japan), $400 \mu \mathrm{M}$ dNTPs, 2.5 $\mathrm{mM} \mathrm{MgCl}$, and $0.2 \mu \mathrm{M}$ of each of the two primers. The temperature program for PCR was one cycle of $3 \mathrm{~min}$ at $95^{\circ} \mathrm{C}, 30$ cycles of $1 \mathrm{~min}$ at $95^{\circ} \mathrm{C}, 60{ }^{\circ} \mathrm{C}$, and 72 ${ }^{\circ} \mathrm{C}$, respectively, and one cycle for $10 \mathrm{~min}$ at $72{ }^{\circ} \mathrm{C}$. The amplified fragment was subsequently isolated from the gel and purified by Gene Clean III Kit (Bio 101). A $1.5 \mathrm{~kb}$ purified fragment was sub-cloned in pCR2.1 vector (Invitrogen, USA), designed pCR2.1-ORF4, and was subsequently transformed to E. coli DH5 $\alpha$. The recombinant plasmid was isolated and digested with $N d e \mathrm{I}$ and $B a m \mathrm{HI}$. The fragment corresponding to the ORF4 was ligated into pET15b expression vector (Novagen, Madison, WI) linierized with $N d e \mathrm{I}$ and $B a m \mathrm{HI}$, to yield a recombinant plasmid, designed as pET15b-ORF4 (Fig. 1). This recombinant plasmid was introduced into $E$. coli $\mathrm{DH} 5 \alpha$ and subsequently isolated and then transformed into $E$. coli BL21 (DE3) pLys as a host strain for gene expression. Transformants were plated on LB plate containing ampicillin $\left(50 \mu \mathrm{g} \mathrm{ml}^{-1}\right)$ and chloramphenicol $\left(25 \mu \mathrm{g} \mathrm{ml}^{-1}\right)$. 


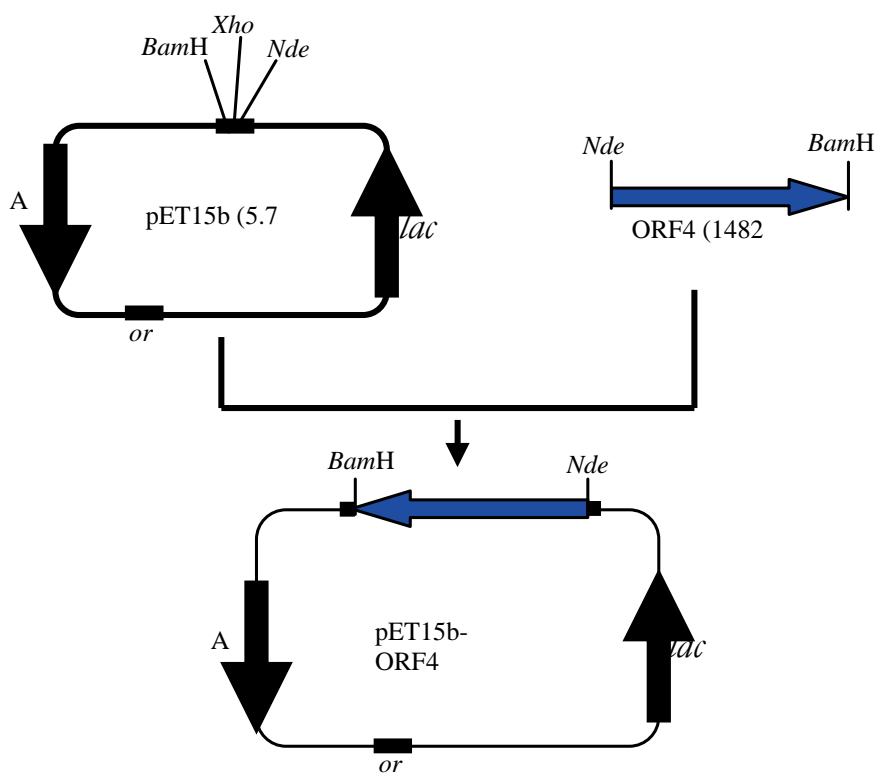

Figure 1. Construction of a recombinant plasmid pET15b-ORF4 $(-7.2 \mathrm{~kb})$.

\section{Purification of ORF4-Histag Fusion Protein}

Ten milliliter culture of E. coli BL21 (DE3) pLysS carrying pET15-ORF4 was induced by $0.1 \mathrm{mM}$ IPTG at $\mathrm{OD}_{600}$ of 0.6 for $3 \mathrm{~h}$. by shaking at $37{ }^{\circ} \mathrm{C}$. The culture was then centrifuged, and pellet was frozen at $-70{ }^{\circ} \mathrm{C}$ until use. The protein was purified under denatured condition using Ni-NTA column (Qiagen, GmbH, Germany).

\section{SDS-PAGE and Western Blotting}

Pellets of uninduced cells $(1 \mathrm{ml})$ and induced cells $(0.5 \mathrm{ml})$, solubilized lysate, or purified-ORF4-Histag fusion protein, were mixed with $2 \mathrm{x}$ sample buffer (Tris. $\mathrm{HCl}$, glycerol, SDS, 2-mercaptoethanol, and bromophenol blue) and denatured by boiling for 5 minutes. SDS-PAGE was performed at $12.5 \%(\mathrm{w} / \mathrm{v})$ acrylamide gel, and protein was stained with commassie brilliant blue. For Western blotting, the ORF4Histag fusion protein polyacrylamide gel was blotted onto a PVDF membrane by electroblotting. The Western blot was stained using monoclonal mouse anti-Histag antibody at 1:5000 dilution. A secondary goat anti-mouse IgG antibody conjugated to alkaline phosphatase was used for imaging (Zymed Laboratories Inc.). 


\section{RESULTS}

\section{Observation of NMA38-4 Cells and Colony}

Colony of this mutant, designated as NMA38-4, was grown on MSGM plate. The color was white indicating the BMP was not synthesized. Whereas the color of the AMB-1 wild type grown on the same media was brown-black. The brown-black color indicated that BMP was synthesized. Observation of NMA38-4 cells under light microscopy showed that cells did not respond to the magnetic fields applied. This indicates BMP may have not been synthesized due presumably to transposon insertion into the genome, especially in the gene involved in BMP synthesis. To confirm this result, NMA38-4 cells were observed by transmission electron microscopy which showed that they did not contain BMPs in the cell (data not shown), indicating that BMPs were not synthesized completely.

\section{DNA Sequence Analysis of ORF4}

Identification of the gene interrupted by mini-Tn 5 transposon in NMA38-4 genome was accomplished by isolation of flanking DNA by inverse PCR, sequencing of the flanking DNA, and sequence analysis through homologous searches of major databases. Figure 2 shows a gel electrophoresis of $1.3 \mathrm{~kb}$ inverse PCR product amplified from DNA flanking the transposon of NMA38-4 genome. To characterize this locus, we used sequence of DNA flanking the transposon aligned against the whole genome sequence of $M$. magneticum AMB-1 (Matsunaga et al. 2005) and assembled one contig which contained mini-Tn5-interrupted gene, ORF4. Homology search of ORF4 sequence by BLASTX program revealed its homology with ABC transporter from Mesorhizobium loti (62\% identity, 74\% similarity). An ORF directly interrupted by transposon, ORF4, with location of transposon insertion site, is shown in Fig. 3. Putative ribosomal binding site (RBS) was found at the position of 7 bp upstream of start codon (ATG).

\section{Amino Acid Sequence Analysis Deduced from the Genes}

The ORF4 of $M$. magneticum AMB-1 encodes a protein of 494 amino acids with molecular mass of $52.8 \mathrm{kDa}$, as shown in Fig. 4. Examination of the deduced amino acid sequence revealed a high degree of homology with $\mathrm{ABC}$ transporter. Further analysis indicated that the sequence contains ATP-binding sites in the ORF4 and the presence of two segment Walker motifs, walker A and B was identified (Walker et al. 1982). The two sequences, GSKKEGKLTCDTMLAL (Walker A) and KVAKPGHRLLMVS (Walker B) were localized in ORF4 at position 170-185 and 309-321, respectively (Fig. 2). The multi alignment of the amino acid sequences revealed a highly conserved region in segment $A$, whereas the consensus in segment

$\mathrm{B}$ was less restrictive, permitting various amino acid substitutions. Analysis of hydrophilicity plot of the protein deduced from ORF4 using an algorithm KiteDoolittle showed that ORF4 protein possessed 10 putative hydrophobic transmembrane $\alpha$ helixes (data not shown). 


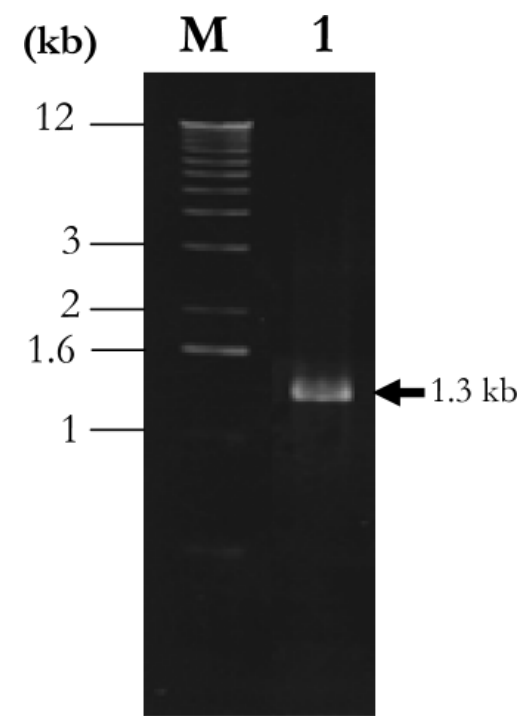

Figure 2. 1.3 kb DNA fragment flanking transposon mini-Tn5Km1 amplified by inverse PCR method (1) and DNA Marker $1 \mathrm{~kb}$ ladder (M).

\section{Expression and Purification of Histag fusion protein}

After recombinant plasmid pET15b-ORF4 was transformed to E. coli BL21 (DE3) pLysS, expression of the ORF4 was induced by addition of $0.1 \mathrm{mM}$ IPTG and under the control of promoter T7 lac. The total protein profile of the whole cells was analyzed by SDS-PAGE to express the Histag-ORF4 fusion protein. As shown in Figure 4A, the protein band $-55 \mathrm{kDa}$ corresponding to the molecular mass of the Histag-ORF4 fusion protein was highly expressed in $E$. coli, and pure protein was obtained after denatured purification. It was confirmed to be the Histag-ORF4 fusion protein by Western blot analysis using anti-Histag antibody (Fig. 4B).

\section{DISCUSSIONS}

In this study, we demonstrated that the gene encoding protein which belongs to ATP binding protein is linked to BMPs synthesis. Mutation of this gene in NMA384 generated non-magnetic cell. The mutant did not respond to the magnetic fields and BMPs were not completely synthesized. Inverse PCR method allowed us to amplify 1.3 $\mathrm{kb}$ genomic flanking DNA from NMA38-4 genome and align the sequence against the whole genome sequence of $M$. magneticum AMB- 1 . The contig containing the sequence of the gene directly interrupted by transposon comprised $1482 \mathrm{bp}$ (Fig. 3). Although this gene did not contain a native promoter, it could be highly expressed in E. coli under T7 lac promoter (Fig. 4). This indicates ORF4 isolated from M. magneticum AMB-1 genome involved in BMPs synthesis could be expressed in Escherichia coli.

Effect of the transposon, not only inactivated the gene directly interrupted, but also the genes located downstream of the transposon insertion (De Bruijn \& Lupski 1984; 
Kleckner et al. 1977). Therefore, ORF4 may most probably have important roles during $\mathrm{BMP}$ synthesis. Interestingly, ORF encodes majority of the protein with functions which is related to ATP-binding cassette $(\mathrm{ABC})$ transporter. Involvement of $\mathrm{ABC}$ transporter in iron transport has been reported in Gram negative and Gram positive bacteria such as Yersinia pestis (Gong et al. 2001; Fetherston et al. 1999; Bearden et al. 1998), Streptococcus pneumoniae (Brown et al. 2001a; Brown et al. 2001b), Neissiria meningitides (Khun et al. 1998), S. pyogenes (Janulczyk et al. 1999), and Brachyspira hyodysenteriae (Dugourd et al. 1999). Taken these all together, it is therefore possible that genes with close homology to ATP-binding protein identified in this study may have a significant role in iron transport during BMPs synthesis after the iron passed across the outer cell membrane.

Despite the significant impact of BMPs to the physiological functions of the cell, information on the mechanisms and the factors affecting their formation is still very limited. Our data suggests that a gene for ATP binding cassette protein and the other genes within the same cluster may most probably be linked to BMPs synthesis in $M$. magneticum AMB-1. This finding may significantly contribute to the complete elucidation of the complex process of BMP synthesis, especially in $M$. magneticum AMB-1.

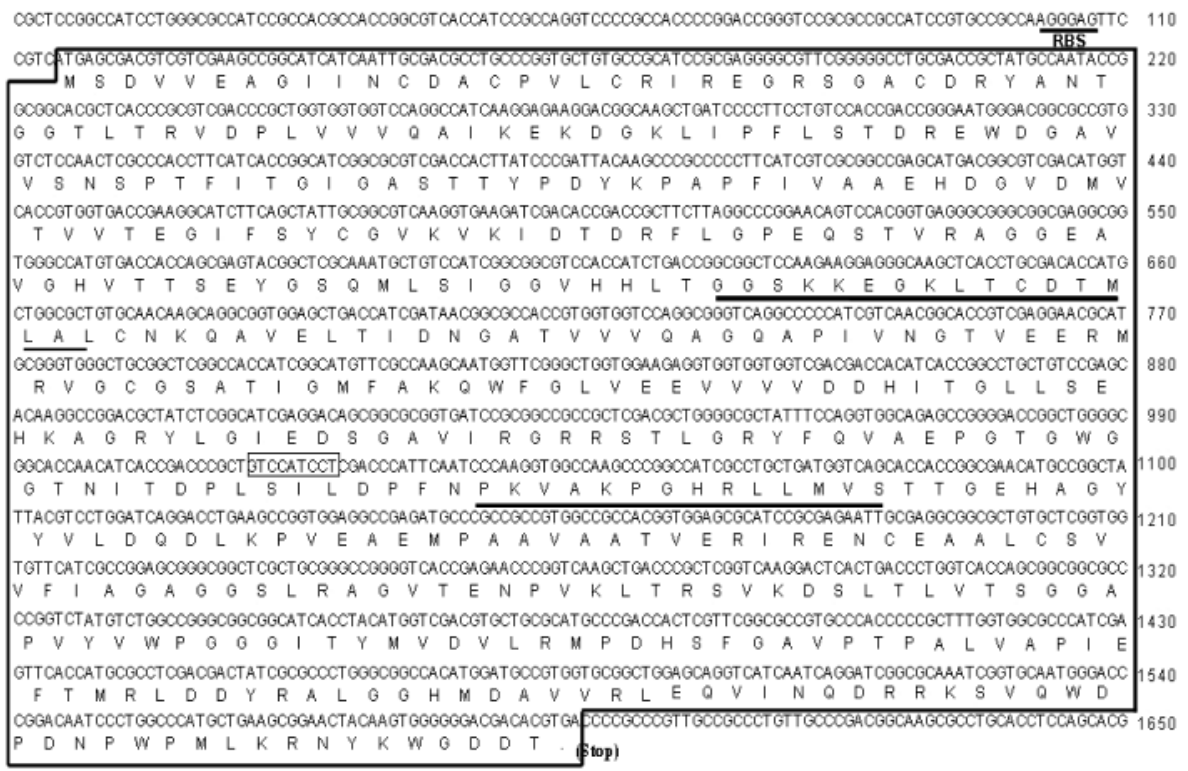

Figure 3. DNA sequence of ORF4 (boxed) started with ATG (start codon) and ended by TGA (stop codon). 9 bases boxed show mini-Tn5 insertion site. Walker A (GGSKKEGKLTCDTMLAL), Walker B (PKVAKPGHRLLMVS), and ribosomal binding site (RBS) are also indicated by underline. 


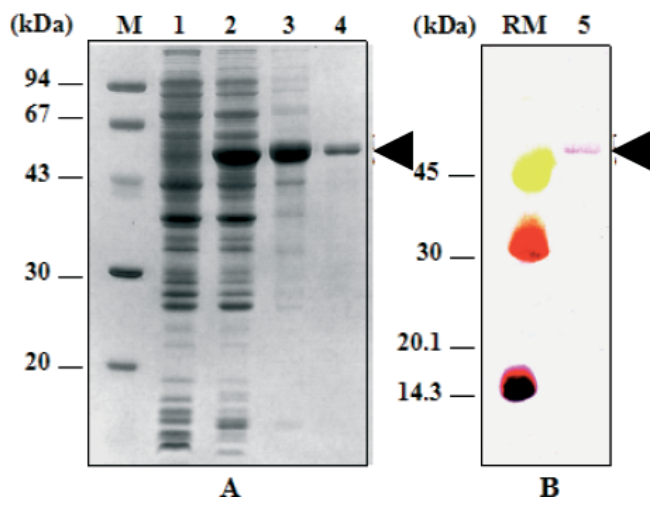

Figure 4. (A). Sodium dodecyl sulfate-polyacrylamide gel electrophoresis (SDS-PAGE) of protein profile of ORF4 expressed in Escherichia coli. Lane M: marker protein. Lane 1: Total cell proteins from uninduced-cells of E. coli BL 21 (DE3) pLysS harboring pET15-ORF4. Lane 2: Total cell proteins from induced-cells of E. coli BL 21 (DE3) harboring pET15-ORF4 induced by 0.1 mM IPTG. Lane 3: Total protein cell lysate $(15 \mu \mathrm{g})$. Lane 4: Purified Histag-ORF4 protein (6 $\mu \mathrm{g})$. (B) Lane RM: Rainbow Marker protein. Lane 5: Western blot analysis of purified HistagORF4 fusion protein $(6 \mu \mathrm{g})$ corresponding to lane 4 .

\section{CONCLUSION}

A gene involved in bacterial magnetic particle synthesis has been isolated from M. magneticum AMB-1 genome, cloned and over-expressed in E. coli BL21 (DE3) pLysS. This gene encoded protein had homology with ABC transporter. A $55 \mathrm{kDa}$ protein corresponding to the gene (ORF4)-Histag fusion protein resulted from the gene expression was detected by SDS-PAGE. The purified protein was confirmed to be ORF4-Histag fusion protein by Western blot analysis. Mutation within this gene (ORF4) rendered M. magneticum AMB-1 defective in bacterial magnetic particle synthesis.

\section{ACKNOWLEDGMENTS}

Part of this work was conducted at Tokyo University of Agriculture and Technology, Japan, especially at Department of Biotechnology (Matsunaga-Takeyama Laboratory). Therefore, I am grateful to Prof Tadashi Matsunaga and Prof Haruko Takeyama for the laboratory facilities and valuable supports.

\section{REFERENCES}

Altchul SF, Madden TL, Scaffer AA, Zhang J, Zhang Z, Miller W, and DJ. Lipman. 1997. Gapped BLAST and PSI-BLAST: a new generation of protein database search programs. Nucleic Acids Research, 25:3389-3402.

Blakemore RP. 1975. Magnetotactic bacteria. Science, 190: 377-379. 
Bacterial magnetic particle synthesis in Magnetospirillum magneticum AMB-1 - Aris Tri Wahyudi.

Blakemore RP, Maratea D, and RS. Wolf. 1979. Isolationand pure culture of a fresh water magnetic spirillum in defined growth medium. Journal of Bacteriology, 140: 720-729.

Bearden SW, Stagg TM, and RD. Perry. 1998. An ABC transporter system of Yersinia pestis allows utilization of chelated iron by Escherichia coli SAB11. Journal of Bacteriology, 180: 1135-1147.

Berson AE, Hudson DV, and NS. Waleh. 1991. Cloning of a sequence of Aquaspirillum magnetotacticum that complements the aroD gene of Escherichia coli. Molecular Microbiology, 5: 2261-2264.

Berson AE, Hudson DV, and NS. Waleh. 1989. Cloning and ccharacterization of the recA gene of Aquaspirillum magnetotacticum. Archives of Microbiology, 152: 567-571.

Brown JS, Ogunniyi AD, Woodrow MC, Holden DW, and JC. Paton. 2001a. Immunization with components of two iron uptake $\mathrm{ABC}$ transporters protects mice against systemic Streptococcus pneumoniae infection. Infection and Immunity, 69: 6702-6706.

Brown JS, Gilliland SM, and DW. Holden. 2001. A Streptococcus pneumoniae pathogenicity island encoding an $\mathrm{ABC}$ transporter involved in iron uptake and virulence. Molecular Microbiology, 40: 572-585.

DeBruijn FJ, and Lupski JR. 1984. The use of transposon Tn 5 mutagenesis in the rapid generation of correlated physical and genetic maps of DNA segments cloned into multi copy plasmids- a review. Gene, 27: 131-149.

Dugourd D, Martin C, Rioux CR, M. Jacques M, and J. Harel. 1999. Characterization of a periplasmic ATPbinding cassette iron import system of Bracyspira (Serpulina) hyodysentriae. Journal of Bacteriology, 181: 6948-6957.

Fetherson JD, Bertolino VJ, and RD. Perry. 1999. YbtP and YbtQ: two ABC transporters required for iron uptake in Yersinia pestis. Molecular Microbiology, 32:289-299.

Gong S, Bearden SW, Geoffroy VA, fetherson JD, and RD. Perry. 2001. Characterization of the Yersinia pestis Yfu ABC inorganic iron transport system. Infection and Immunity, 67: 2829-2837.

Gorby YA, Beveridge TJ, and RP. Blakemore RP. 1988. Characterization of the bacterial magnetosome membrane. Journal of Bacteriology, 170: 834-841.

Janulczyk R, Pallon J, and L. Bjorck. 1999. Identification and characterization of Streptococcus pyogenes ABC transporter with multiple specificity for metal cations. Molecular Microbiology, 34: 596-606.

Khun HH, Kirby SD, and BC. Lee. 1998. A Neisseria meningitidis fbpABC mutant is incapable of using nonheme iron for growth. Infection and Immunity, 66: 2330-2336.

Klecker N, Roth J, and D. Botstein. 1977. Genetic engineering in vivo using translocatable drug-resistance element: new method in bacterial genetic. Journal of Molecular Biology, 116: 125-159.

Matsunaga T. 1991. Application of bacterial magnets. Trends in Biotechnology, 9: 91-95.

Matsunaga T, Sakaguchi T, and F. Todokoro. 1991. Magnetite formation by a magnetic bacterium capable of growing aerobically. Applied Microbiology and Biotechnology, 35: 651-655.

Matsunaga T, Nakamura C, Burgess JG, and K. Sode. 1992. Gene transfer in magnetic bacteria: Transposon mutagenesis and cloning of genomic DNA fragments required for magnetite synthesis. Journal of Bacteriology, 174: 2748-2753.

Nakamura C, Burgess JG, Sode K, and T. Matsunaga. 1995a. An iron-regulated gene, magA, encoding an iron transport protein of Magnetospirillum sp. AMB-1. Journal of Biological Chemistry, 270: 2839228396.

Okamura Y, Takeyama H, and T. Matsunaga. 2001. A magnetosome-specific GTPase from the magnetic bacterium Magnetospirillum magneticum AMB-1. Journal of Biological Chemistry, 276: 4818348188.

Okuda Y, Denda K, and Y. Fukumori. 1996. Cloning and sequencing of a gene encoding a new member of the tetratricopeptide protein family from magnetosome of Magnetospirillum magnetotacticum. Gene, 171: 99102 . 
BIOTROPIA Vol. 16 No. 1, 2009

Schleifer KH, Schuler D, Sprins S, Weinegger M, Amann R, Ludwig W, and M. Kohler. 1991. The genus Magnetosporillum, gen. Nov., description of Magnetospirillum gryphiswaldense and transfer of Aquaspirillum magnetotacticum to Magnetospirillum magnetotacticum, comb. nov. Systematic and Applied Microbiology, 14: 379-385.

Wahyudi AT, Takeyama H, and T. Matsunaga. 2001. Isolation of Magnetospirillum magneticum AMB-1 mutants defective in bacterial magnetic particle synthesis by transposon mutagenesis. Applied Biochemistry and Biotechnology, 91: 147-154.

Walker JM, Sarsate M, Runswick MJ, and JJ. Gay. 1982. Distantly related sequences in the A and B-subunits of ATP synthase, myosin, kinases, and other ATP-requiring enzymes and common nucleotide binding fold. EMBO Journal, 1: 945-951. 
Thank you for evaluating AnyBizSoft PDF Splitter.

A watermark is added at the end of each output PDF file.

To remove the watermark, you need to purchase the software from

http://www.anypdftools.com/buy/buy-pdf-splitter.html 